\title{
Scientific Knowledge Graph and Trend Analysis of Central Sensitization: A Bibliometric Analysis
}

\author{
Zhuo $\mathrm{Li}^{1,2, *}$, Chi $\mathrm{Xu} \mathbb{D}^{2, *}$, Jun $\mathrm{Fu}^{2}$, Maimaiti Zulipikaer $\mathbb{D}^{2}$, Tao Deng ${ }^{2}$, Jiying Chen ${ }^{2}$ \\ 'School of Medicine, Nankai University, Tianjin, People's Republic of China; ${ }^{2}$ Department of Orthopedic Surgery, Chinese PLA General Hospital, \\ Beijing, People's Republic of China \\ *These authors contributed equally to this work \\ Correspondence: Jiying Chen, Department of Orthopedic Surgery, Chinese PLA General Hospital, No. 28 Fuxing Road, Haidian District, Beijing, \\ 100853, People's Republic of China, Tel +8610 66938104, Fax +8610 68216336, Email jiyingchen_301@I63.com
}

\begin{abstract}
Background: Central sensitization refers to a state of hypersensitivity in the central nervous system and is associated with the development and maintenance of chronic pain. Central sensitization plays an essential role in various diseases. Nevertheless, there has been no bibliometric analysis before in this field. The purpose of this study was to provide critical themes and trends in the area of central sensitization, to build a network of knowledge, and to facilitate the future development of relevant basic and clinical research.
\end{abstract}

Methods: Publications on central sensitization were extracted from the Science Citation Index-Expanded. We used R software to systematically analyze the countries, institutions, authors, journals, references, and keywords of the publications. Besides, conceptual structure, intellectual structure, and social structure were constructed.

Results: A total of 4466 publications were included. Research in the field of central sensitization generally showed a steady upward trend. The three structural networks showed that the United States is the leading country in this field. Arendt-Nielsen L and Woolf CJ were the most productive and influential authors, respectively. "Pain" was the journal with the most studies. Most journals that published and cited articles about central sensitization were academically influential. Cluster analysis revealed that research in central sensitization contains three main conceptual clusters, and the themes of research evolve frequently. Current research focuses on the pathogenesis of central sensitization in neuropathic pain, the role of central sensitization in different diseases, and related clinical double-blind trials.

Conclusion: Central sensitization received widespread attention. The United States led the way in academic activity. In this field, the current situation of cooperation and communication between different countries and institutions is positive. The present research hotspots were the pathogenesis of central sensitization in neuropathic pain, the role of central sensitization in different diseases, and related clinical double-blind trials.

Keywords: central sensitization, bibliometric analysis, pain, co-word, co-citation, collaboration network

\section{Introduction}

Pain is one of the most common clinical symptoms, leading to a decrease in the quality of life and an increase in health care expenditures. ${ }^{1,2}$ In the United States alone, approximately 100 million adults suffer from chronic pain and it costs $\$ 600$ billion each year. $^{3}$ Nowadays, more and more researches focus on the central sensitization (CS) of pain. CS, formally proposed by Woolf et al in 1988, refers to a state of hypersensitivity in the nervous system and is associated with the development and maintenance of chronic pain. ${ }^{4}$ In the state of CS, pain-related signaling pathways are hypersensitive to noxious and non-noxious stimuli. Besides, CS plays a crucial role in the evolution from acute to chronic pain. ${ }^{5}$ To a certain extent, pain is a measure of self-protection. However, chronic pain in a pathological state can be extremely disturbing to physical and mental health. When CS occurs, the nervous system is "provoked". It is in a constant state of hyperresponsiveness, which lowers the pain threshold and continues to maintain pain after the external stimulus has disappeared or diminished. 
CS can be present in many conditions with chronic pain, including fibromyalgia, ${ }^{6}$ endometriosis, ${ }^{7}$ chronic low back pain, ${ }^{8,9}$ hidradenitis suppurativa, ${ }^{10}$ osteoarthritis, ${ }^{6,11}$ rheumatoid arthritis and chronic migraine. ${ }^{12}$ Besides, complex regional pain syndrome (CRPS), also known as Sudeck's atrophy, is also highly associated with CS and is characterized by significant autonomic and inflammatory features. ${ }^{13,14}$ In addition, in procedures such as hip and knee arthroplasty, spinal fusion, ovariohysterectomy, and oral surgery, CS can aggravate postoperative pain and severely reduce the postoperative quality of life. ${ }^{15-21}$

In terms of pathogenesis, CS is a broad topic that encompasses distorted sensory processing in the central nerve system (CNS), ${ }^{22}$ malfunctioning of descending pain-inhibitory mechanisms, ${ }^{23}$ enhanced activity of pain-facilitatory mechanisms, ${ }^{24}$ and long-term potentiation of the neural synapses in the anterior cingulate cortex. ${ }^{25}$ The abovementioned pathological conditions will gradually lead to CS. This process can start with peripheral sensitization and then progress to advanced CS characterized by allodynia and diffuse hyperalgesia. ${ }^{26}$ Synaptic plasticity, influenced by environmental and individual genetic factors, is a critical element in CS process. Moreover, neuroplasticity in chronic pain syndromes has been of great interest to clinicians and researchers in recent decades.

Bibliometrics is a cross-cutting discipline that uses mathematical and statistical methods to quantitatively analyze a variety of specific indicators such as authors, citations, and keywords of the literature. With its help, we can also construct a network of knowledge in a particular field. Unlike other methods, bibliometrics can provide more accurate and credible reports through a systematic, reproducible, and modular process of literature analysis. It can simultaneously manage and handle large amounts of literature information, uncover intrinsic connections in the data, reveal the current state and development process of the discipline, and present the current scientific landscape of the research field. ${ }^{27,28}$

Bibliometric analysis has been applied in cutting-edge medical fields, such as COVID-19 ${ }^{29}$ and single-cell sequencing. ${ }^{30}$ To the best of our knowledge, this is the first bibliometric study in the field of CS. The purpose of this study was to provide critical themes and trends in the area of CS, to build a network of knowledge, to get an overview of academic collaborations, and to facilitate the future development of relevant basic and clinical research.

\section{Materials and Methods}

The data for this study were extracted from the Science Citation Index Expanded (SCI-EXPANDED) database of the Clarivate Analytics Web of Science Core Collection. The data search strategy included the topic "central sensitization", and the time span was set to 1998-2020. A total of 4710 articles were retrieved. Two other authors independently reviewed the titles and abstracts of the literature. We excluded special types of publications such as book chapters, editorial materials, corrections, and proceedings papers, and obtained a total of 4466 articles for further analysis. We exported 4466 articles in the form of all records and references and saved them as BibTex files. All data were downloaded within one day on September 15, 2021 to avoid deviations caused by database updates.

We summarized and analyzed the main bibliometric indicators of the selected literature, including the number of articles, journals, keywords, citations, author distribution, and collaborations. We used Author Appearances (AA) to represent the total frequency of all authors in all publications. Besides, we calculated the collaboration index (CI), which is another metric used to quantify collaboration between authors and can be calculated as total authors of multi-authored articles/total multi-authored articles. Besides, we used total citations and local citations to assess the impact of the articles. The former counts citations received by a selected article "all over the world", while the latter counts only citations received from documents included in our collection (4466 articles). Local citations measure the impact of a document in the analyzed collection. What's more, we assessed the author's scholarly achievements by H-index, G-index, and M-index. It is well known that H-index is an author's number of published articles (h) each of which has been cited in other papers at least $\mathrm{h}$ times. The $\mathrm{m}$-index is defined as $\mathrm{H}$-index/n, where $\mathrm{n}$ is the number of years since the first published paper of the author. Additionally, given a set of articles ranked in decreasing order of the number of citations that they received, the G-index is the unique largest number such that the top $\mathrm{g}$ articles received together at least $\mathrm{g}^{2}$ citations. In further, we evaluated the academic impact of the journals based on Journal Citation Reports (JCR). Briefly, journals in a field are ranked according to their impact factors, with the top $25 \%$ (including $25 \%$ ) being classified as Q1, the top $25 \%$ to $50 \%$ (including $50 \%$ ) as Q2, the top $50 \%$ to $75 \%$ (including $75 \%$ ) as Q3, and those after $75 \%$ as Q4. As for keywords, there were two types of keywords: those provided by the authors and those automatically extracted 
by the system (KeyWord Plus). KeyWords Plus provides additional search terms extracted from the titles of articles cited by authors in their bibliographies and footnotes in the ISI (now Clarivate Analytics) database. It substantially augments title-word and author-keyword indexing. ${ }^{31}$

Additionally, we constructed three structural networks to enable deeper mining of the literature structure. Nodes in the network represented high-frequency items (eg, articles, journals, or authors), and their sizes indicated the frequency of occurrence. The more frequently an item appears, the larger the size of the corresponding node. Similarly, the lines between nodes represented their connectivity or interactions. The thickness of the line reflected the degree or strength of co-citation or co-occurrence of the nodes. ${ }^{32,33}$ We applied three metrics to measure the centrality of nodes in the network. All shortest paths of any two nodes in the network were calculated, and if many of them passed through a node, then the Betweenness Centrality of this node was considered high. If the shortest distance from a node to other nodes was small, then we considered the Closeness Centrality of the node to be high. The PageRank score was obtained by link analysis, which was an unsupervised learning method based on Markov chains on graph data. ${ }^{34}$

The conceptual structure was constructed by co-word analysis based on the co-occurrence frequency of keywords in the whole set. More specifically, it was mapped using the co-occurrence of KeyWords Plus. We set the following parameters: the normalization method was the association, the number of nodes was 50, the repulsion force was 0.1 , the minimum number of edges was 2, and we removed isolated nodes. In addition, we constructed the intellectual structure of the CS field by co-citation analysis. Co-citation can be seen as the counterpart of bibliographic coupling. As far as references are concerned, two articles are coupled if at least one common citation source appears in the references of both articles. Co-citation, on the other hand, reflects two cited papers being cited by one paper at the same time. The bibliographic coupling reflects a fixed and long-lasting relationship between the papers, while the co-citation reflects a changing or temporary relationship. We set the number of nodes to 50 and constructed a co-citation network of articles, authors, and journals. Besides, we showed the social structure of the CS by collaboration network analysis. The nodes in the network can represent articles, journals, institutions, or countries, and they were linked by co-authors.

Data processing and analysis were performed by $\mathrm{R}$ software (version 4.1.0). We completed the bibliometric analysis and plotted figures using the R package called bibliometrix. For cluster analysis, the Louvain method was chosen as the algorithm. ${ }^{35}$

\section{Results}

\section{General Information and Publication Trends}

As shown in Figure 1 and Table 1, 4466 publications on CS have been published in the past 23 years. During this 23-year period, there had been a substantial increase in the number of papers on CS. The overall analysis of the publications showed that they were written by 13,127 authors and the average citations per document were 40.1 . These publications had 833 journals and a total of 119,823 references. Besides, the number of KeyWords Plus and author's keywords were 8643 and 6850 , respectively. Interestingly, the average article citations per year fluctuated around four with two peaks: in 2004 and 2019 with 8.2 and 5.8, respectively, indicating that newly published articles also had a high impact.

\section{Publication Performances: Countries, Institutions, and Authors}

The publication country was selected based on the corresponding author. As shown in Table 2, the most productive country in terms of CS was the United States of America (USA) $(n=1379,30.9 \%)$, followed by China $(n=432,9.7 \%)$ and Germany $(\mathrm{n}=262,5.9 \%)$. However, although the United States has the largest number of multiple countries publications (MCPs), it does not account for a high percentage of all publications. The most cited country was also USA ( $\mathrm{n}=87,030$, average article citations (AAC, total citations divided by the number of articles) $=63.11$ ), followed by the United Kingdom $(\mathrm{n}=11,313$, AAC $=45.07)$ and Germany $(\mathrm{n}=10,977, \mathrm{AAC}=41.9)$. The top three most productive institutions were University of Florida $(\mathrm{n}=297)$, Aalborg University $(\mathrm{n}=269)$ and Vrije Universiteit Brussel $(\mathrm{n}=232)$ (Figure 2A). Six of the top ten most productive institutions were in the USA. The above data showed that the USA was the leader in CS research. In addition, Figure 2B showed the top ten most productive authors, and Figure 2C showed their annual articles published and cited information. Many authors had been deeply involved in the field of CS for more than 


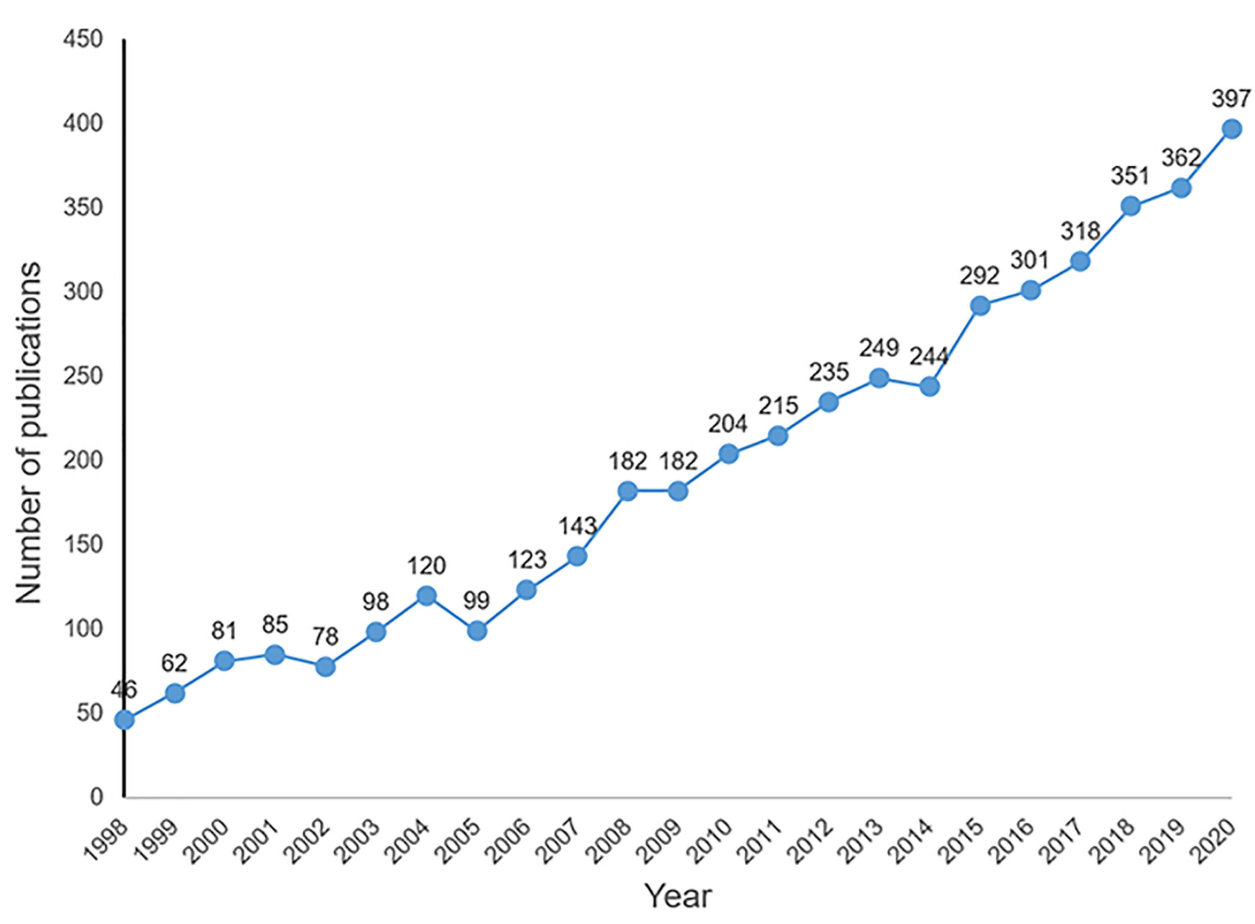

Figure I The number of publications with the theme of CS indexed by SCI-E from 1998 to 2020. Abbreviations: CS, central sensitization; SCI-E, Science Citation Index-Expanded.

ten years. From 1998 to 2020, Arendt-Nielsen L had published articles on CS almost every year. Nijs J and Meeus M, on the other hand, had been focusing on CS field research since 2007, while academic publications were more prolific after 2013. We analyzed authors' academic indices (H-index, G-index, and M-index) based on this study's article collection. Arendt-Nielsen L from Aalborg University not only had the highest number of publications but also had the highest academic indices (Supplementary Table 1).

\section{Highly Contributive Journals and Articles}

The most productive source for article publication was "Pain" with 380 articles published during 1998-2020, followed by "Journal of Pain" ( $n=118)$ and "European Journal of Pain" $(n=116)$ (Table 3). Most of the journals were in the field of pain research or neuroscience journals. Besides, the articles from "Pain" were the most cited, with 24,854 total citations. More importantly, the most cited journals in the references of 4466 included publications were also "Pain" with 29,410 citations. Most local cited articles referred to highly cited articles in the current data set, and can be considered as articles with significant academic influence in this field. The first ranked article was "Woolf et al, 2011"26 with 748 local citations and 2014 global citations, followed by "Latremoliere et al, 2009"36 with 664 local citations and 1731 global citations (Supplementary Table 2). Both review articles were published on "Pain".

\section{Conceptual Structure}

Based on the co-occurrence analysis of $8643 \mathrm{KeyWords}$ Plus, we revealed that they can be classified into three different clusters (Figure 3). We ranked them in each cluster based on their network centrality. In cluster 1, "central sensitization" (Betweenness Centrality:121.20) had the highest centrality, followed by "pain" and "hyperalgesia". Cluster 2 contained only two elements, "sensitization" and "central". However, cluster 3 revealed another topic closely linked to CS: "neuropathic pain" (Betweenness Centrality:21.58). "Spinal-cord", "neurons", and "activation" also belonged to the same cluster (Supplementary Table 3). We divided the 23-year time span of articles into three periods: 1998-2005; 20062012; and 2013-2020. As shown in Figure 4, in the first period of 1998-2005, we identified 12 thematic fields, of which "substance-p" and "central sensitization" were the most studied. In the second phase, the field of "neuropathic pain" 
Table I Main Information About Bibliometric Analysis

\begin{tabular}{|l|c|}
\hline Description & Results \\
\hline Data & \\
Timespan & $1998: 2020$ \\
Journals & 833 \\
Documents & 4466 \\
Average years from publication & 8.51 \\
Average citations per documents & 40.1 \\
Average citations per year per doc & 3.881 \\
References & 119823 \\
Document types & \\
Original article & 3654 \\
Review & 812 \\
Document contents & \\
Keywords Plus & 8643 \\
Author's Keywords & 6850 \\
Authors & \\
Authors & 13127 \\
Author Appearances & 21792 \\
Authors of single-authored documents & 219 \\
Authors of multi-authored documents & 12908 \\
Authors collaboration & \\
Single-authored documents & 284 \\
Documents per Author & 0.34 \\
Authors per Document & 2.94 \\
Co-Authors per Documents & 4.88 \\
Collaboration Index & 3.09 \\
\hline
\end{tabular}

emerged, which evolved from the previous nine thematic areas. "Temporal summation", which evolved from three thematic areas, was also an important emerging concept during this period. Interestingly, in the recent period, many of the previous fields evolved into the final five key areas: "central sensitization", "neuropathic pain", " double-blind", "sensitization", "low-back-pain", and "brain". These were the hot research topics and future directions in the field of CS.

\section{Intellectual Structure}

The most influential authors, articles, and journals were determined based on co-citation networks and cluster analysis. In articles and authors clustering, we obtained four main clusters, while in journals we obtained two (Figure 5). Figure 5A showed that "Woolf CJ", "Arendt-Nielsen L", "Burstein R" and "Treede RD" occupied the center of each of the four author clusters. The top five co-cited authors with the highest Betweenness Centrality were "Woolf CJ" (118.06) in cluster 1, and "Treede RD" (50.30), "Koltzenburg M" (34.07), "Melzack R" (31.42), and "Baron R" (26.11) in cluster 4 (Supplementary Table 4). "Price DD" (22.72) and "Burstein R" (13.78) were the most centralized in clusters 2 and 3, respectively. Figure 5B indicated that "Woolf CJ, 2011" and "Latremoliere A" were centered in the largest cluster of articles. In fact, six of the top 10 co-cited articles with the highest centrality were written by Woolf CJ, and these articles were in the center of cluster 1, cluster 2, and cluster 4. As for the co-cited journals, the "Journal of Neuroscience" and the "Pain" are the most centralized in clusters 1 and 2, respectively (Figure 5C). However, the "Pain" was the most centralized by a large margin. Most of the journals in cluster 1 were neuroscience journals, while the journals in cluster 2 seemed to be more focused on pain research. The above results indicated that "Woolf CJ" and the "Pain" were the most influential author and journal in the co-citation network, respectively. 
Table 2 Top 20 Productive Countries and Citations per Country

\begin{tabular}{|c|c|c|c|c|c|c|c|c|}
\hline $\begin{array}{l}\text { Sort by } \\
\text { NP }\end{array}$ & Country & Articles (\%) & SCP & MCP (\%) & $\begin{array}{l}\text { Sort by Total } \\
\text { Citations }\end{array}$ & Country & $\begin{array}{l}\text { Total } \\
\text { Citations }\end{array}$ & $\begin{array}{l}\text { Average Article } \\
\text { Citations }\end{array}$ \\
\hline Ist & USA & 1379 (30.9) & 1172 & $207(15.0)$ & Ist & USA & 87030 & 63.11 \\
\hline 2nd & China & $432(9.7)$ & 346 & $86(20.0)$ & 2nd & $\begin{array}{l}\text { United } \\
\text { Kingdom }\end{array}$ & 11313 & 45.07 \\
\hline $3 r d$ & Germany & $262(5.9)$ & 196 & $66(25.2)$ & $3 r d$ & Germany & 10977 & 41.9 \\
\hline 4th & $\begin{array}{l}\text { United } \\
\text { Kingdom }\end{array}$ & $25 I(5.6)$ & 187 & $64(25.5)$ & 4th & Denmark & 10968 & 51.98 \\
\hline 5th & Denmark & $211(4.7)$ & $13 \mid$ & $80(37.9)$ & 5 th & China & 7935 & 18.37 \\
\hline 6th & Canada & $188(4.2)$ & $14 \mid$ & $47(25)$ & 6th & Canada & 7217 & 38.39 \\
\hline 7th & Italy & $186(4.2)$ & $15 \mid$ & $35(18.8)$ & 7th & Belgium & 5298 & 32.7 \\
\hline 8th & Spain & I73(3.9) & 82 & $91(52.6)$ & 8th & Italy & 4878 & 26.23 \\
\hline 9th & Belgium & $162(3.6)$ & 96 & $66(40.7)$ & 9th & Spain & 4377 & 25.3 \\
\hline 10th & Japan & $154(3.5)$ & 129 & $25(16.2)$ & 10th & Japan & 4054 & 26.32 \\
\hline IIth & Australia & $138(3.1)$ & 95 & $43(31.2)$ & II th & France & 3436 & 32.11 \\
\hline 12th & Brazil & $110(2.5)$ & 64 & $46(41.8)$ & 12 th & Australia & 3252 & 23.57 \\
\hline 13th & France & $107(2.4)$ & 89 & $18(16.8)$ & 13th & Israel & 2127 & 45.26 \\
\hline 14th & Korea & $107(2.4)$ & 85 & $22(20.6)$ & 14th & Switzerland & 2090 & 41.8 \\
\hline 15th & Netherlands & $101(2.3)$ & 67 & $34(33.7)$ & 15 th & Netherlands & 2004 & 19.84 \\
\hline 16th & Sweden & $63(1.4)$ & 37 & $26(4 \mid .3)$ & 16 th & Brazil & 1999 & 18.17 \\
\hline 17th & Switzerland & $50(I .1)$ & 20 & $30(60)$ & 17th & Sweden & 1919 & 30.46 \\
\hline 18th & Israel & $47(1.1)$ & 42 & $5(10.6)$ & 18th & Korea & 1785 & 16.68 \\
\hline $19 \mathrm{tn}$ & Norway & $40(0.9)$ & 33 & $7(17.5)$ & $19 \mathrm{tn}$ & Norway & 1212 & 30.3 \\
\hline 20th & Turkey & $40(0.9)$ & 35 & $3(7.9)$ & 20th & Ireland & 658 & 41.12 \\
\hline
\end{tabular}

Abbreviations: NP, number of publications; MCP, multiple countries publications (inter-country collaboration); SCP, single country publications (intra-country collaboration).

\section{Social Structure}

Ten different clusters of authors were formed in the social structure of 4466 articles related to CS (Figure 6A). The authors with high centrality in the co-collaboration network were "Arendt-Nielsen L" in Cluster 1, "Nijs J" in Cluster 2, "Wang Y" in Cluster 3, and "Ji RR" in Cluster 4. Besides, the institutions reaching the highest centrality were "Aalborg University", "Vrije Universiteit Brussel", "Harvard University", and "The University of Toronto" (Figure 6B). The most prominent countries with high centrality were the USA (619.21) in cluster 1, United Kingdom (54.87) in cluster 2, Spain (21.87) in cluster 3 (Figure 6C). China was in the same cluster as the US and also had a high degree of centrality (48.62). Simultaneously, we constructed an inter-country collaboration map based on the number of MCPs. In brief, it was created by mapping MCPs' international partnerships to a global map to more visually show the state of global collaboration. The thicker the red line, the more frequent the collaboration. As shown in Figure 7, international cooperation in the field of CS was quite frequent. Specifically, the top five collaborations among countries, ranked by number of MCPs, were USA-China:100; USA-United Kingdom:68; USA-Germany:59; USA-Canada:53; USA-Denmark:47. The social structure suggested a good level of international collaboration in the field of CS, with the USA playing an influential role in the cooperation network.

\section{Discussion}

We applied a bibliometric analysis to elucidate the global scientific activity around the topic of CS to help scholars deepen their understanding of the scientific accumulation and potential future trends in CS research. We analyzed the most productive countries, institutions and authors, and the most contributive journals and articles in CS research. Besides, we constructed conceptual structure, knowledge structure, and social structure through network analysis and cluster analysis. To the best of our knowledge, this is the first bibliometric study in the field of CS. 
Table 3 Top 20 Journals Related to Central Sensitization

\begin{tabular}{|c|c|c|c|c|c|}
\hline Sort by Number of Articles & Relevant Sources & Articles & TC & JCR & IF (2020) \\
\hline Ist & Pain & 380 & 24854 & QI & 6.961 \\
\hline 2nd & Journal of Pain & 118 & 6214 & QI & 5.820 \\
\hline $3 r d$ & European Journal of Pain & 116 & 3563 & Q2 & 3.931 \\
\hline 4th & Neuroscience & 109 & 3870 & Q3 & 3.590 \\
\hline 5th & Molecular Pain & 105 & 2968 & Q3 & 3.395 \\
\hline 6th & Pain Medicine & 101 & 2390 & Q2 & 3.750 \\
\hline 7th & Clinical Journal of Pain & 85 & 3041 & Q2 & 3.442 \\
\hline 8th & Journal of Neuroscience & 84 & 8961 & QI & 6.167 \\
\hline 9th & Neuroscience Letters & 75 & 1477 & Q3 & 3.046 \\
\hline I0th & Cephalalgia & 74 & 10642 & QI & 6.292 \\
\hline II th & PLoS One & 71 & 1587 & Q2 & 3.240 \\
\hline I2th & Headache & 66 & 2787 & QI & 5.887 \\
\hline I3th & Anesthesiology & 57 & 3513 & QI & 7.892 \\
\hline I4th & Journal of Neurophysiology & 57 & 2744 & Q3 & 2.714 \\
\hline 15th & Brain Research & 54 & 1607 & Q3 & 3.252 \\
\hline 16th & Journal of Pain Research & 49 & 615 & Q3 & 3.133 \\
\hline 17th & Anesthesia and Analgesia & 45 & 2669 & QI & 5.108 \\
\hline 18th & Experimental Neurology & 44 & 1824 & Q2 & 5.330 \\
\hline $19 \mathrm{tn}$ & Pain Practice & 44 & 1117 & Q3 & 3.183 \\
\hline 20th & Current Pain and Headache Reports & 43 & 1428 & Q2 & 3.494 \\
\hline
\end{tabular}

Abbreviations: JCR, Journal Citation Reports; IF, impact factor; TC, total citations.

It is well known that in recent years there had been a significant increase in the number of publications in the field of pain, such as pain after spinal cord injury, ${ }^{37}$ chronic postsurgical pain, ${ }^{38}$ etc. As shown in Figure 1, the number of CS-related articles was on a very steady upward trend, which indicated a great potential for future development. The USA was the most productive and most cited country. Besides, six of the top ten most productive institutions were in the USA. The above data showed that the USA is the leader in CS research. Similarly, bibliometric analyses in other specific pain areas had shown the USA was the leader in pain research, such as pain in the elderly, ${ }^{39}$ back pain, ${ }^{40}$ acupuncture for low back pain, ${ }^{41}$ and neuropathic pain. ${ }^{42}$ Many of the most productive authors had been deeply involved in this field for more than ten years, reflecting the progressive development of their research. In recent years, Arendt-Nielsen L, as the most productive author, had contributed to elucidating the role of CS in tension-type headache, chronic neck and shoulder pain, pelvic pain, and osteoarthritis pain. ${ }^{43-47}$ Regarding the number of publications and the citations, "Pain" was the most influential journal. Besides, 7 of the top 20 most productive journals belonged to JCR Q1, which showed the importance of CS field research.

Most local cited articles can provide us with more helpful information. Two reviews written by Woolf and Latremoliere described in detail the concept and mechanisms of CS. They elaborated on its relationship to central neuroplasticity and implications for the diagnosis and treatment of pain. ${ }^{26,36} \mathrm{Ji}$ et al analyzed the molecular mechanisms underlying the generation and maintenance of CS and learning memory. ${ }^{48}$ Notably, they suggested that although synaptic plasticity changes differ between the two, they share striking similarities. Using patch-clamp recordings in lamina II neurons of isolated spinal cord slices, pro-inflammatory cytokines (interleukin-1 $\beta$, interleukin-6, and tumor necrosis factor- $\alpha$ ) had been shown to induce CS through distinct and overlapping synaptic mechanisms in superficial dorsal horn neurons. ${ }^{49}$ In addition, these cytokines may further induce long-term synaptic plasticity through cAMP response elementbinding protein (CREB)-mediated downstream responses. The study by Arendt-Nielsen et al revealed the role of CS in painful knee osteoarthritis and received 518 global citations and 167 local citations. ${ }^{50}$

In the conceptual structure we constructed, the essential clusters were cluster 1: "Central Sensitization" and cluster 2: "Neuropathic Pain". The concepts in both clusters have been very active over the past 20 years: cluster 1 - which includes the terms pain, mechanism, hyperalgesia, modulation, and temporal summation - is the most prominent and 
A

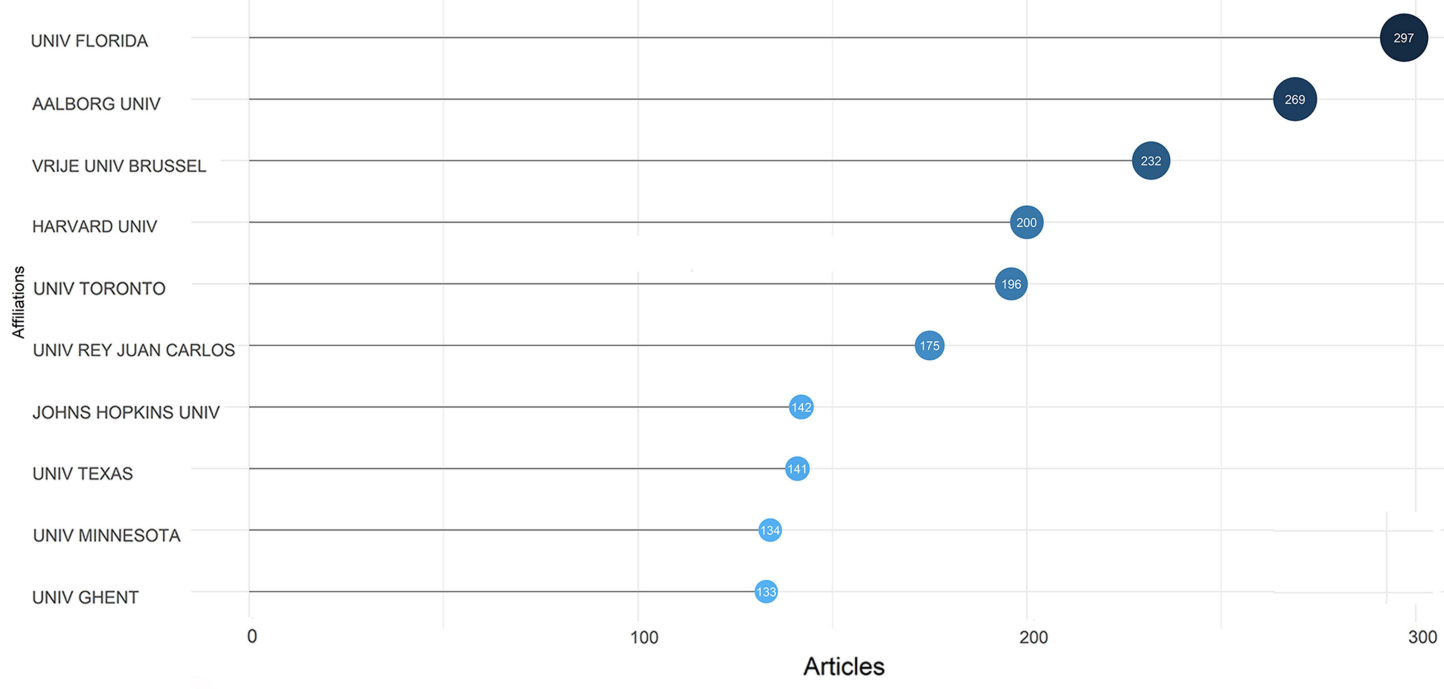

B

ARENDT-NIELSEN L

NIJS J

MEEUS M

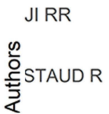

FERNANDEZ-DE-LAS-PENAS C

SESSLE BJ

TREEDE RD

WANG J

WILLIS WD

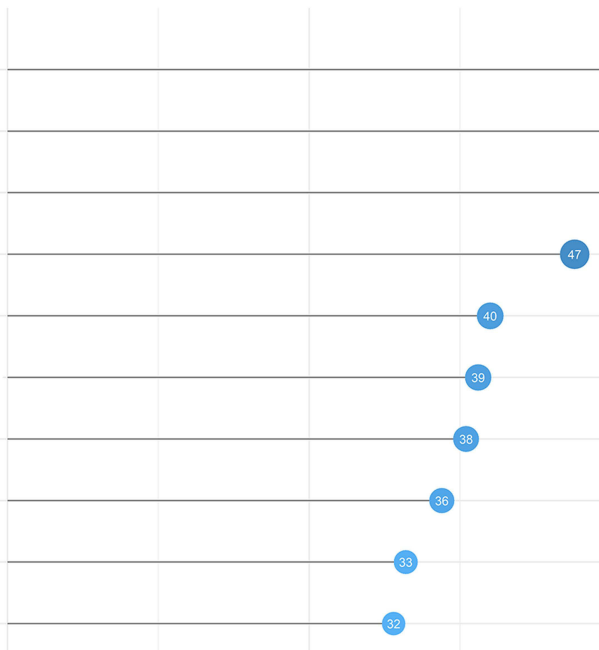

$\begin{array}{ll}0 & 25\end{array}$

50

C

N. of Documents

75

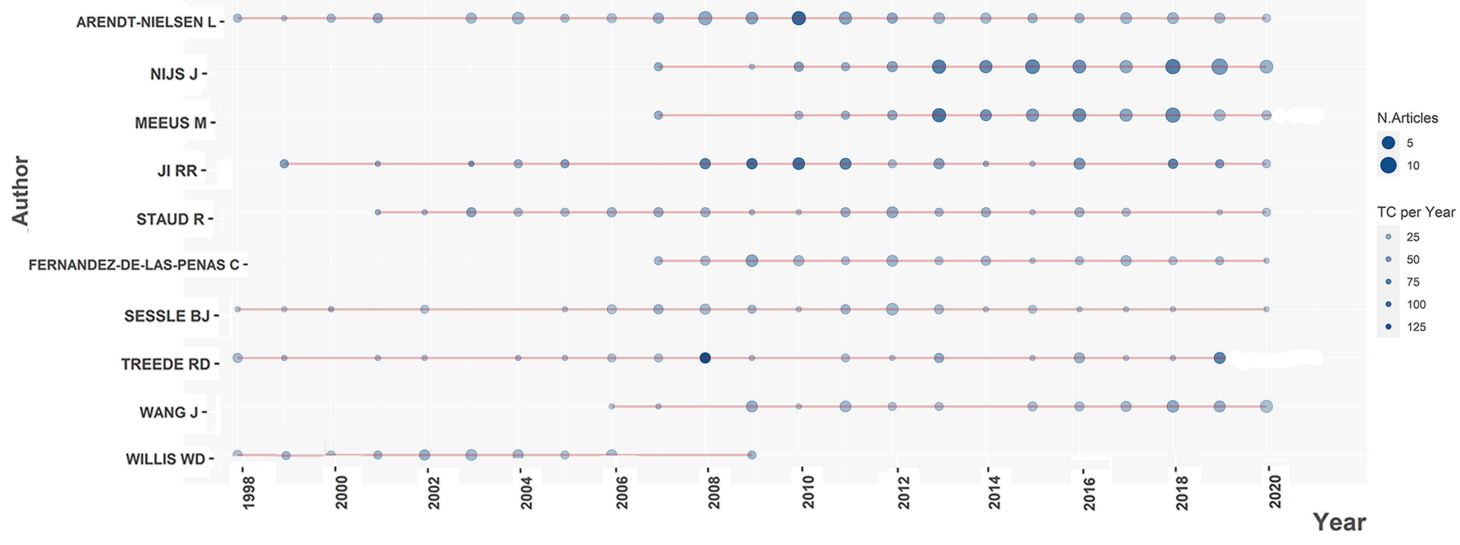

Figure 2 Top ten most productive institutions and authors. (A) Top ten most productive institutions; (B) Top ten most productive authors; (C) Top-Authors' Production Over Time. The color of the dots represent the number of articles, and the size of the dots represent the TC per year.

Abbreviation: TC, total citations. 


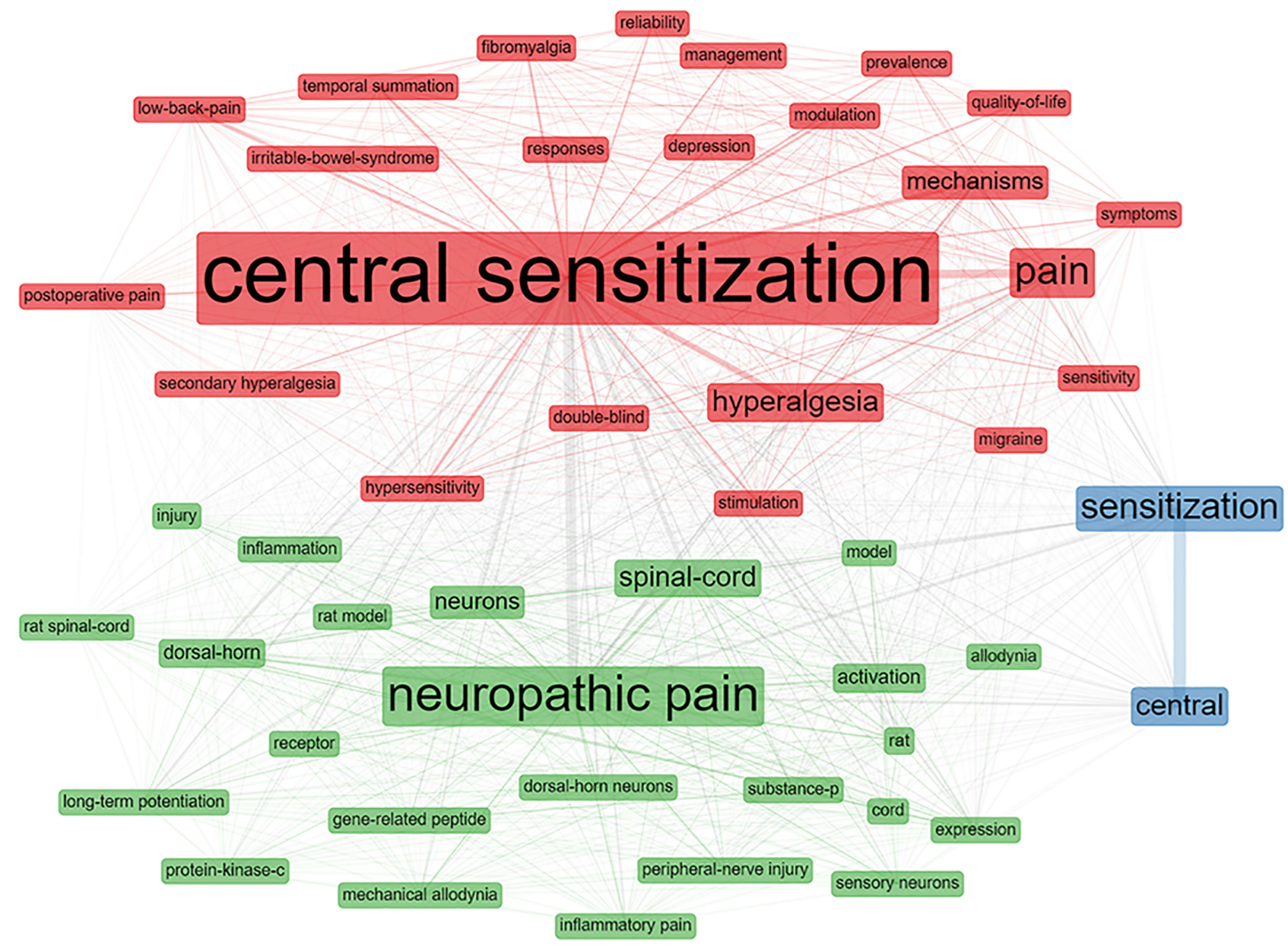

Figure 3 Network visualization of KeyWords Plus (KWP) co-occurrence. The thickness of the connecting line between 2 keywords represents the strength of cooccurrence. The size of the KWP represents the index of their centrality.

demonstrates the core concepts of the CS field. As well, another primary cluster "Neuropathic Pain" - which includes the terms spinal cord, neurons, activation, substance-p, long-term potentiation, and peripheral nerve injury - mainly explores the neuropathological alterations of $\mathrm{CS}^{26,51-53} \mathrm{We}$ analyzed the thematic evolution of different time slices, which can highlight the complexity of research in the CS field. Interestingly, in the recent period, many of the previous fields evolved into the final five key fields: "central sensitization", "neuropathic pain", "double-blind", "sensitization", "low-back-pain", and "brain ". Several bibliometric analyses showed similar interesting results. "Double blind" was also one of the most commonly used keywords in neuropathic pain research. ${ }^{42}$ Besides, "central sensitization" was the research development trends and focus in the pain field after spinal cord injury. ${ }^{37}$ Nowadays, there are a growing number of double-blind studies advancing the clinical application of the concept of CS, deepening the understanding of a variety of diseases such as osteoarthritis and migraine. ${ }^{54-57}$ CS-related changes in functional brain activity can be observed in rats with endometriosis-related pain: enhanced ReHo signaling in the cingulate cortex, thalamus, and hippocampus, which may be due to neuronal apoptosis or hyperactivity. ${ }^{58}$ In addition, since the brain-derived neurotrophic factor (BDNF) is an essential driver of neuroplasticity, targeting BDNF may be a potential therapeutic target for improving CS (blockade of the adenosine A2A receptor, antagonizing NMDA receptors, or blocking the proteinase-activated receptors $2-\mathrm{NK}-\kappa \beta$ signaling pathway). ${ }^{59}$ The importance of CS in chronic low back pain has been demonstrated. Similarly, in acute lower back pain CS may co-exist with other psychological factors (high sensitivity and negative psychological state) and contribute to the persistence of pain. ${ }^{60}$

Intellectual structure analysis revealed the current knowledge base of CS research, and it indicated that "Woolf CJ" and the "Pain" were the most influential author and journal in the co-citation network, respectively. Although "Woolf CJ" 


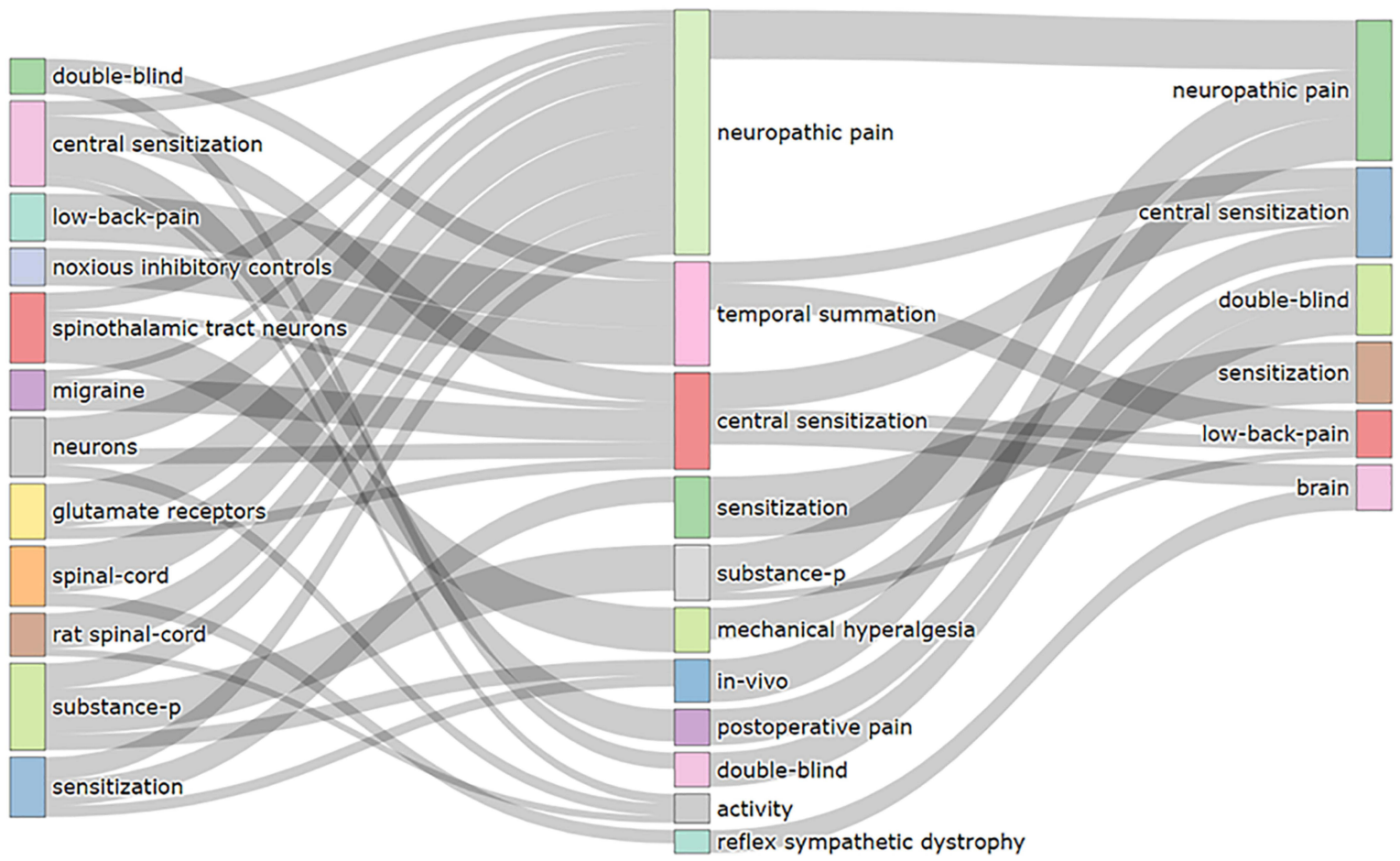

Figure 4 Thematic evolution of KeyWords Plus in field of research on central sensitization 1998-2020. Three time slices: 1998-2005, 2006-2012, and 20I3-2020.

A

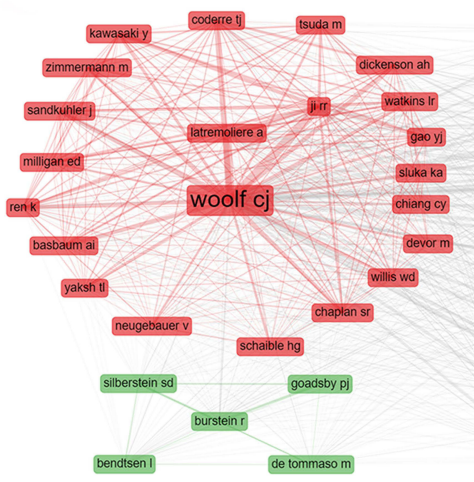

B

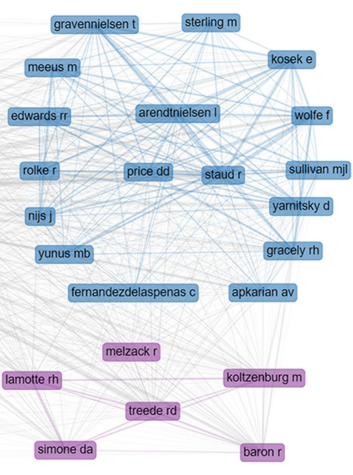

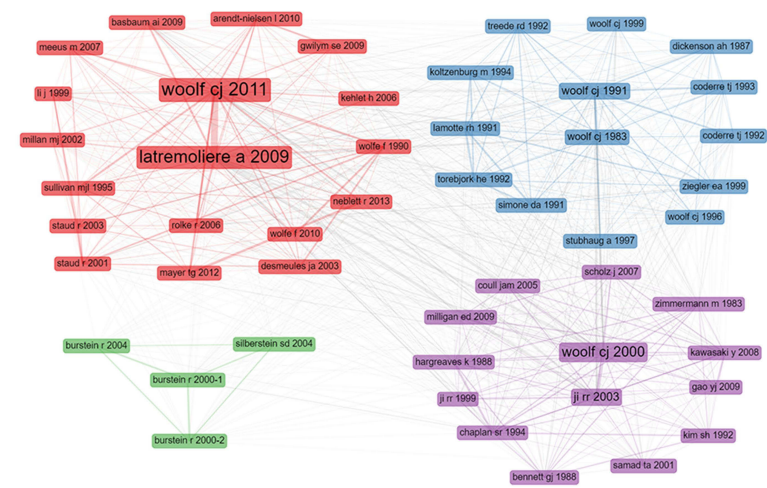

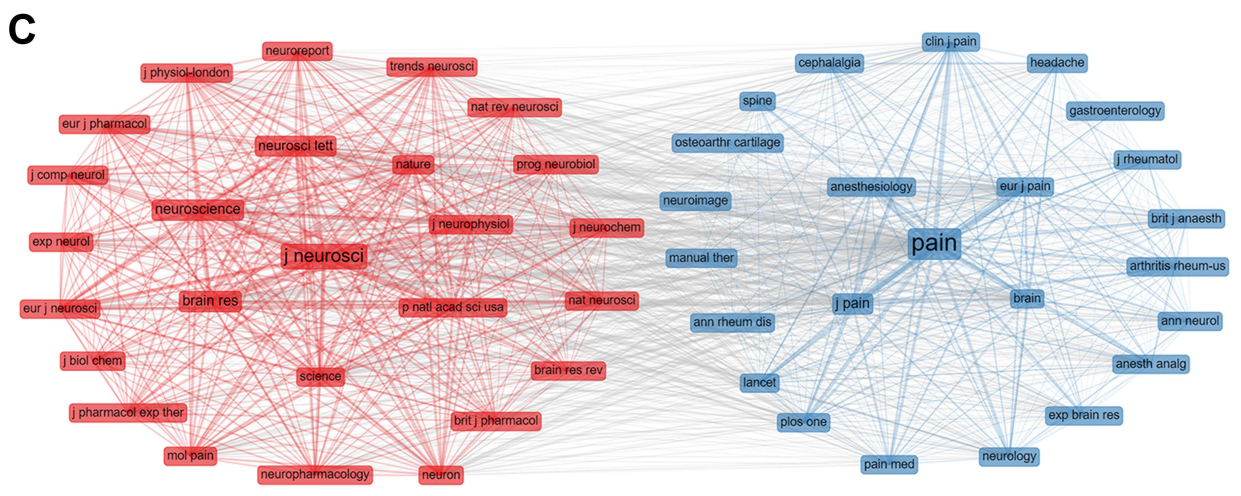

Figure 5 Co-citation network analysis with the identification of only 2 co-citation clusters for (A) authors, (B) articles, and (C) journals. 
A

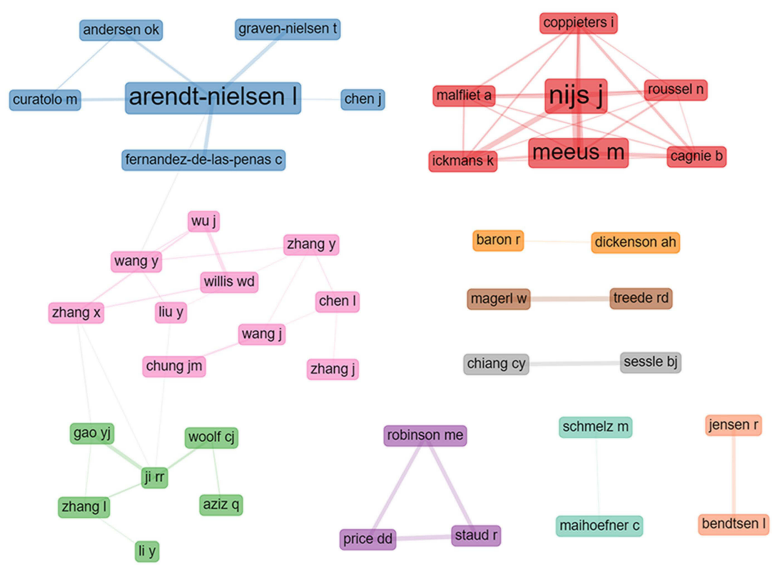

B

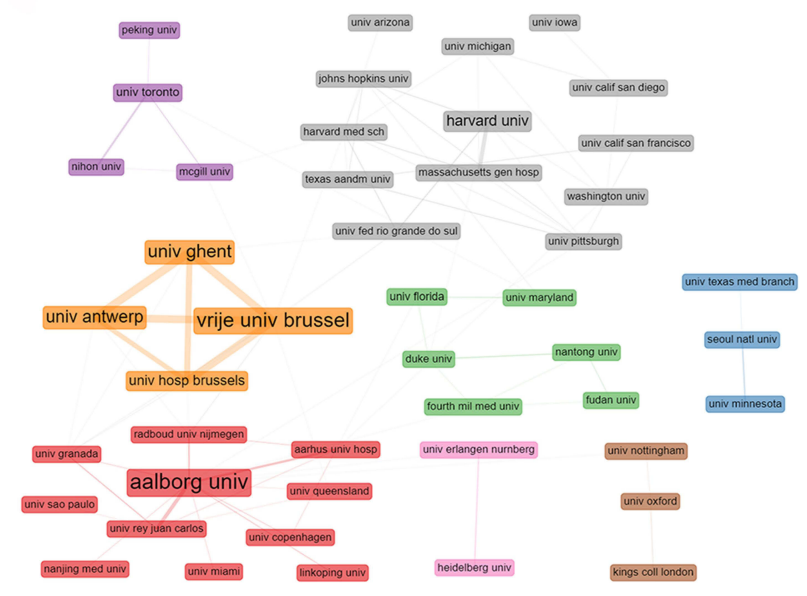

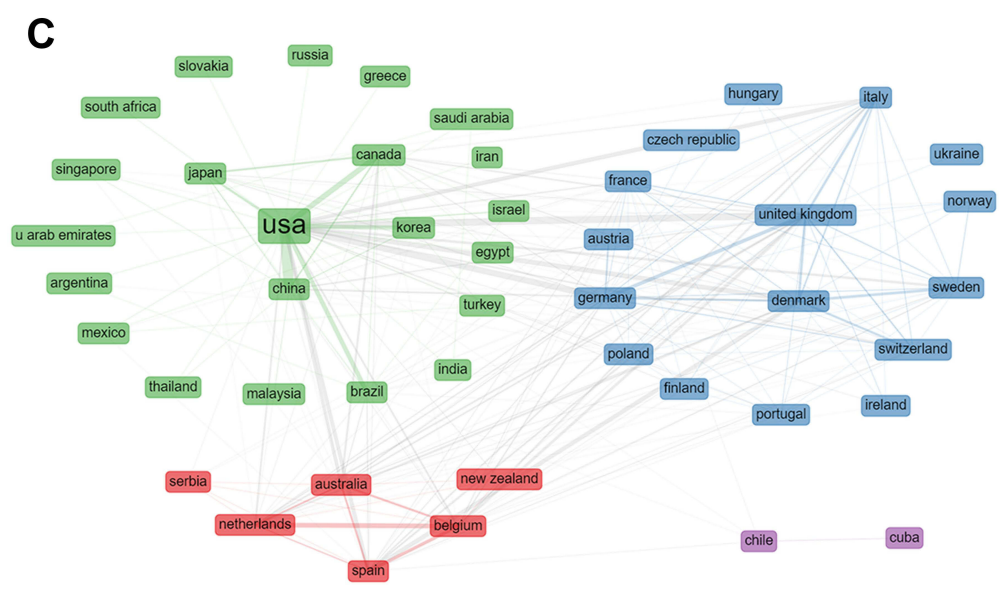

Figure 6 Collaborations network among (A) authors, (B) institutions, and (C) countries.

is not on the list of the most productive authors, his papers have a considerable impact on the CS field. The most contributive article is "Woolf et al, 2011" with 748 local citations and 2011 global citations, which can also confirm the significance of his publications. He revealed that IL1 $\beta$-mediated induction of Cox-2 in the central nervous system promoted hypersensitivity of inflammatory pain. ${ }^{61}$ Besides, he confirmed that bradykinin activated multiple kinases in dorsal horn neurons resulting in hyperalgesia. ${ }^{62}$ On a more fundamental level, the papers located at the center of each cluster in Figure 5B can represent recognized carriers of knowledge in the CS field. At the same time, they can also contribute to the emergence of new research.

We constructed social structures at three levels: authors, research institutions, and countries. What is exciting is that there is a good co-collaboration network in the CS field, especially between countries, which is not available in some other studies. ${ }^{32}$ But we should also note the imbalance between the different geographic regions: North America, Europe, East Asia, and Oceania are the regions where collaboration is much more frequent. The lack of deeper international cooperation may be a real obstacle to more remarkable progress in CS research in the future. With the help of academic journals and professional associations, it is proposed that scholars from different research areas and professional backgrounds should work collaboratively to optimize this situation further. ${ }^{63}$

The present study also has some limitations that need to be solved. First, we only included articles from the Web of Science Core Collection; therefore, this study cannot be an exhaustive review of the entire literature in the CS field. Second, the search results of this study are not representative of the real-time situation due to the continuous updating of the relevant literature. Third, although the publications included in this study were manually screened, the quality of the collected literature was uneven, which may reduce the credibility of the results. It is undoubtedly important to select as 


\section{Country Collaboration Map}

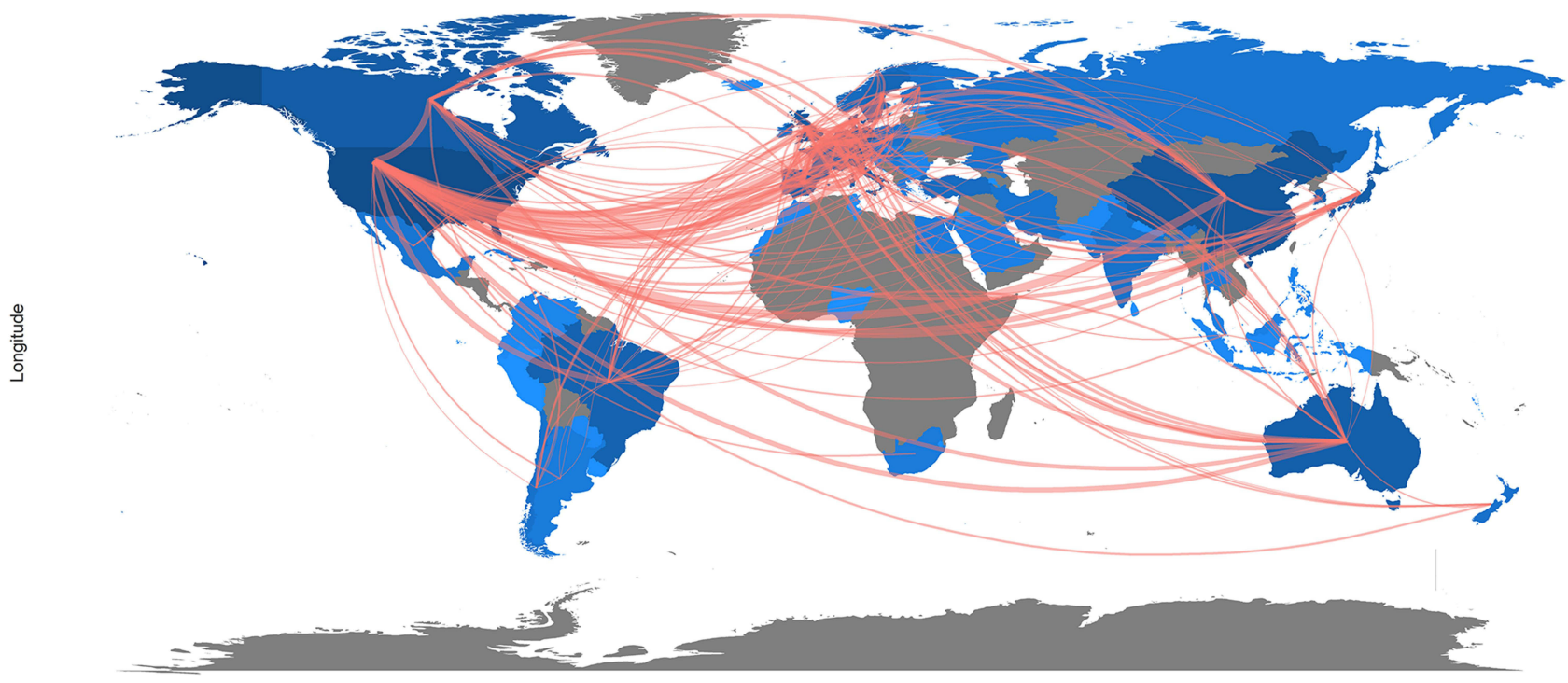

Latitude

Figure 7 Worldwide collaborations among countries in the field of central sensitization. The thicker the red line, the more frequent the collaboration.

much relevant publications as possible in order to obtain an overall picture of research in a given field. Therefore, stringent inclusion criteria for the publications may be a double-edged sword. In future studies we may be able to assess or avoid the uneven quality of the literature by setting different inclusion criteria, classification according to different definitions of CS, or based on impact factor or number of citations, etc. Fourth, CS can only be assessed in animals and in humans we can only assess a proxy, which may introduce uncertainty into the results. In future research, we may be able to precisely define CS in humans or animals separately and analyze it separately. Finally, we cannot assess the incidence of self-citation when constructing the knowledge structure.

Our study was based on the R package "bibliometrix", and three structural networks were constructed. Overall, we established a model that can be used to keep track on the area in the future with the option to see changes in the landscape. Through periodic analysis, we can obtain historical trajectories and real-time dynamics of CS research. We hope this is an innovative exploration in this field.

\section{Conclusion}

Studying the mechanism of CS and its role in disease diagnosis and treatment has excellent research value and broad clinical application prospects. Using the R package named bibliometrix for bibliometric analysis and visualization, research in CS generally showed a steady upward trend. The three structural networks showed that the USA is the leading country in this research. Arendt-Nielsen L and Woolf CJ were the most productive and influential authors, respectively. The current situation of cooperation and communication between different countries and institutions is positive. Most journals that publish and cite articles about CS were academically influential, indicating that CS had received widespread attention. Cluster analysis revealed that research in the field of CS contained three main conceptual clusters, and the themes of research evolved frequently. The current research focused on the pathogenesis of CS in neuropathic pain, the role of CS in different diseases, and related clinical double-blind trials.

\section{Abbreviations}

CS, central sensitization; CNS, central nerve system; SCI-EXPANDED, Science Citation Index Expanded; BDNF, brainderived neurotrophic factor; KWP, KeyWords plus; MCP, multiple countries publications. 


\section{Data Sharing Statement}

The raw data can be directly obtained from the Web of Science Core Collection (WoSCC) database.

\section{Ethics Approval and Informed Consent}

This study did not include any patient information. Thus, the requirement for ethics approval was waived.

\section{Acknowledgments}

This work was supported by National Key Research and Development Program of China (No. 2020YFC2004900).

\section{Disclosure}

Zhuo Li and Chi Xu are the co-first authors. The authors report no conflicts of interest in this work.

\section{References}

1. Stockbridge EL, Suzuki S, Pagan JA. Chronic pain and health care spending: an analysis of longitudinal data from the Medical Expenditure Panel Survey. Health Serv Res. 2015;50(3):847-870. doi:10.1111/1475-6773.12263

2. Vartiainen P, Heiskanen T, Sintonen H, Roine RP, Kalso E. Health-related quality of life and burden of disease in chronic pain measured with the 15D instrument. Pain. 2016;157(10):2269-2276. doi:10.1097/j.pain.0000000000000641

3. Dzau VJ, Pizzo PA. Relieving pain in America: insights from an Institute of Medicine committee. JAMA. 2014;312(15):1507-1508. doi:10.1001/ jama.2014.12986

4. Woolf CJ, Thompson SW, King AE. Prolonged primary afferent induced alterations in dorsal horn neurones, an intracellular analysis in vivo and in vitro. J Physiol (Paris). 1988;83(3):255-266.

5. Noel M, Palermo TM, Chambers CT, Taddio A, Hermann C. Remembering the pain of childhood: applying a developmental perspective to the study of pain memories. Pain. 2015;156(1):31-34. doi:10.1016/j.pain.0000000000000001

6. Lopez-Ruiz M, Losilla JM, Monfort J, et al. Central sensitization in knee osteoarthritis and fibromyalgia: beyond depression and anxiety. PLoS One. 2019;14(12):e0225836. doi:10.1371/journal.pone.0225836

7. Orr NL, Wahl KJ, Lisonek M, et al. Central sensitization inventory in endometriosis. Pain. 2021;163:e234-e245.

8. Giesecke T, Gracely RH, Grant MA, et al. Evidence of augmented central pain processing in idiopathic chronic low back pain. Arthritis Rheum. 2004;50(2):613-623. doi:10.1002/art.20063

9. Akeda K, Takegami N, Yamada J, Fujiwara T, Nishimura A, Sudo A. Central sensitization in chronic low back pain: a Population-Based Study of a Japanese Mountain Village. J Pain Res. 2021;14:1271-1280. doi:10.2147/JPR.S301924

10. Aarts P, Aitken JJ, van Straalen KR. Prevalence of central sensitization in patients with hidradenitis suppurativa. JAMA Dermatol. $2021 ; 157: 1209$. doi:10.1001/jamadermatol.2021.2918

11. Chappell AS, Ossanna MJ, Liu-Seifert H, et al. Duloxetine, a centrally acting analgesic, in the treatment of patients with osteoarthritis knee pain: a 13-week, randomized, placebo-controlled trial. Pain. 2009;146(3):253-260. doi:10.1016/j.pain.2009.06.024

12. Niu Y, Zeng X, Qin G, Zhang D, Zhou J, Chen L. Downregulation of metabotropic glutamate receptor 5 alleviates central sensitization by activating autophagy via inhibiting mTOR pathway in a rat model of chronic migraine. Neurosci Lett. 2021;743:135552. doi:10.1016/j.neulet.2020.135552

13. Eldufani J, Elahmer N, Blaise G. A medical mystery of complex regional pain syndrome. Heliyon. 2020;6(2):e03329. doi:10.1016/j.heliyon.2020. e03329

14. Goebel A. Complex regional pain syndrome in adults. Rheumatology. 2011;50(10):1739-1750. doi:10.1093/rheumatology/ker202

15. Bennett EE, Walsh KM, Thompson NR, Krishnaney AA. Central sensitization inventory as a predictor of worse quality of life measures and increased length of stay following spinal fusion. World Neurosurg. 2017;104:594-600. doi:10.1016/j.wneu.2017.04.166

16. Juhl GI, Jensen TS, Norholt SE, Svensson P. Central sensitization phenomena after third molar surgery: a quantitative sensory testing study. Eur J Pain. 2008;12(1):116-127. doi:10.1016/j.ejpain.2007.04.002

17. Kaka U, Rahman NA, Abubakar AA, et al. Pre-emptive multimodal analgesia with tramadol and ketamine-lidocaine infusion for suppression of central sensitization in a dog model of ovariohysterectomy. J Pain Res. 2018;11:743-752. doi:10.2147/JPR.S152475

18. Kim MS, Koh IJ, Choi KY, Seo JY, In Y. Minimal clinically important differences for patient-reported outcomes after TKA depend on central sensitization. J Bone Joint Surg Am. 2021;103(15):1374-1382. doi:10.2106/JBJS.20.02138

19. Kim MS, Koh IJ, Sohn S, Kang BM, Kwak DH, In Y. Central sensitization is a risk factor for persistent postoperative pain and dissatisfaction in patients undergoing revision total knee arthroplasty. J Arthroplasty. 2019;34(8):1740-1748. doi:10.1016/j.arth.2019.03.042

20. Koh IJ, Kang BM, Kim MS, Choi KY, Sohn S, In Y. How does preoperative central sensitization affect quality of life following total knee arthroplasty? J Arthroplasty. 2020;35(8):2044-2049. doi:10.1016/j.arth.2020.04.004

21. Wylde V, Sayers A, Odutola A, Gooberman-Hill R, Dieppe P, Blom AW. Central sensitization as a determinant of patients' benefit from total hip and knee replacement. Eur J Pain. 2017;21(2):357-365. doi:10.1002/ejp.929

22. Staud R, Craggs JG, Robinson ME, Perlstein WM, Price DD. Brain activity related to temporal summation of C-fiber evoked pain. Pain. 2007;129 (1-2):130-142. doi:10.1016/j.pain.2006.10.010

23. Meeus M, Nijs J, Van de Wauwer N, Toeback L, Truijen S. Diffuse noxious inhibitory control is delayed in chronic fatigue syndrome: an experimental study. Pain. 2008;139(2):439-448. doi:10.1016/j.pain.2008.05.018

24. Meeus M, Nijs J. Central sensitization: a biopsychosocial explanation for chronic widespread pain in patients with fibromyalgia and chronic fatigue syndrome. Clin Rheumatol. 2007;26(4):465-473. doi:10.1007/s10067-006-0433-9

25. Zhuo M. A synaptic model for pain: long-term potentiation in the anterior cingulate cortex. Mol Cells. 2007;23(3):259-271. 
26. Woolf CJ. Central sensitization: implications for the diagnosis and treatment of pain. Pain. 2011;152(3 Suppl):S2-S15. doi:10.1016/j. pain.2010.09.030

27. Durieux V, Gevenois PA. Bibliometric indicators: quality measurements of scientific publication. Radiology. 2010;255(2):342-351. doi:10.1148/ radiol.09090626

28. Ellegaard O, Wallin JA. The bibliometric analysis of scholarly production: how great is the impact? Scientometrics. 2015;105(3):1809-1831. doi:10.1007/s11192-015-1645-z

29. Xia D, Yao R, Wang S, Chen G, Wang Y. Mapping trends and hotspots regarding clinical research on COVID-19: a bibliometric analysis of global research. Front Public Health. 2021;9:713487. doi:10.3389/fpubh.2021.713487

30. Wang Q, Yang KL, Zhang Z, et al. Characterization of global research trends and prospects on single-cell sequencing technology: bibliometric analysis. J Med Internet Res. 2021;23(8):e25789. doi:10.2196/25789

31. Chong Y, Long X, Ho YS. Scientific landscape and trend analysis of keloid research: a 30-year bibliometric review. Ann Transl Med. 2021;9 (11):945. doi:10.21037/atm-21-508

32. Fortuna G, Aria M, Piscitelli A, Mignogna MD, Klasser GD. Global research trends in complex oral sensitivity disorder: a systematic bibliometric analysis of the structures of knowledge. J Oral Pathol Med. 2020;49(6):565-579. doi:10.1111/jop.13077

33. Gonzalez-Alcaide G, Calafat A, Becona E, Thijs B, Glanzel W. Co-citation analysis of articles published in substance abuse journals: intellectual Structure and Research Fields (2001-2012). J Stud Alcohol Drugs. 2016;77(5):710-722. doi:10.15288/jsad.2016.77.710

34. Brin S, Page L. The anatomy of a large-scale hypertextual Web search engine. Comput Netw ISDN Syst. 1998;30(1):107-117. doi:10.1016/S01697552(98)00110-X

35. Subelj L, Bajec M. Unfolding communities in large complex networks: combining defensive and offensive label propagation for core extraction. Phys Rev E Stat Nonlin Soft Matter Phys. 2011;83(3 Pt 2):036103. doi:10.1103/PhysRevE.83.036103

36. Latremoliere A, Woolf CJ. Central sensitization: a generator of pain hypersensitivity by central neural plasticity. $J$ Pain. $2009 ; 10(9): 895-926$. doi:10.1016/j.jpain.2009.06.012

37. Wang YZ, Wu CC, Wang XQ. Bibliometric Study of Pain after Spinal Cord Injury. Neural Plast. 2021;2021:6634644. doi:10.1155/2021/6634644

38. Li Q, Dai W, Chen X, Su D, Yu W, Gu X. Publication trends and hot spots in chronic postsurgical pain (CPSP) research: a 10-year bibliometric analysis. J Pain Res. 2021;14:2239-2247. doi:10.2147/JPR.S300744

39. Zhao Y, Zhang Z, Guo S, et al. Bibliometric analysis of research articles on pain in the elderly published from 2000 to 2019 . J Pain Res. 2021;14:1007-1025. doi:10.2147/JPR.S283732

40. Huang W, Wang L, Wang B, Yu L, Yu X. Top 100 cited articles on back pain research: a citation analysis. Spine. $2016 ; 41(21)$ :1683-1692. doi:10.1097/BRS.0000000000001736

41. Liang YD, Li Y, Zhao J, Wang XY, Zhu HZ, Chen XH. Study of acupuncture for low back pain in recent 20 years: a bibliometric analysis via CiteSpace. J Pain Res. 2017;10:951-964. doi:10.2147/JPR.S132808

42. Xiong HY, Liu H, Wang XQ. Top 100 most-cited papers in neuropathic pain from 2000 to 2020 : a Bibliometric Study. Front Neurol. 2021;12:765193. doi:10.3389/fneur.2021.765193

43. Arendt-Nielsen L, Morlion B, Perrot S, et al. Assessment and manifestation of central sensitisation across different chronic pain conditions. Eur J Pain. 2018;22(2):216-241. doi:10.1002/ejp.1140

44. Grundstrom H, Gerdle B, Alehagen S, Bertero C, Arendt-Nielsen L, Kjolhede P. Reduced pain thresholds and signs of sensitization in women with persistent pelvic pain and suspected endometriosis. Acta Obstet Gynecol Scand. 2019;98(3):327-336. doi:10.1111/aogs.13508

45. Iwabuchi SJ, Xing Y, Cottam WJ, et al. Brain perfusion patterns are altered in chronic knee pain: a spatial covariance analysis of arterial spin labelling MRI. Pain. 2020;161(6):1255-1263. doi:10.1097/j.pain.0000000000001829

46. Monteiro BP, Otis C, Del Castillo JRE, et al. Quantitative sensory testing in feline osteoarthritic pain - A systematic review and meta-analysis. Osteoarthritis Cartilage. 2020;28(7):885-896. doi:10.1016/j.joca.2020.04.006

47. Petersen KK, Olesen AE, Simonsen O, Arendt-Nielsen L. Mechanistic pain profiling as a tool to predict the efficacy of 3-week nonsteroidal anti-inflammatory drugs plus paracetamol in patients with painful knee osteoarthritis. Pain. 2019;160(2):486-492. doi:10.1097/j. pain.0000000000001427

48. Ji RR, Kohno T, Moore KA, Woolf CJ. Central sensitization and LTP: do pain and memory share similar mechanisms? Trends Neurosci. 2003;26 (12):696-705. doi:10.1016/j.tins.2003.09.017

49. Kawasaki Y, Zhang L, Cheng JK, Ji RR. Cytokine mechanisms of central sensitization: distinct and overlapping role of interleukin-1beta, interleukin-6, and tumor necrosis factor-alpha in regulating synaptic and neuronal activity in the superficial spinal cord. $J$ Neurosci. 2008;28 (20):5189-5194. doi:10.1523/JNEUROSCI.3338-07.2008

50. Arendt-Nielsen L, Nie H, Laursen MB, et al. Sensitization in patients with painful knee osteoarthritis. Pain. 2010;149(3):573-581. doi:10.1016/j. pain.2010.04.003

51. Meacham K, Shepherd A, Mohapatra DP, Haroutounian S. Neuropathic pain: central vs. peripheral mechanisms. Curr Pain Headache Rep. 2017;21 (6):28. doi:10.1007/s11916-017-0629-5

52. Silva RL, Lopes AH, Guimaraes RM, Cunha TM. central sensitization. Neurobiol Dis. 2017;105:109-116. doi:10.1016/j.nbd.2017.06.001

53. Wang F, Ma SB, Tian ZC, et al. Nociceptor-localized cGMP-dependent protein kinase I is a critical generator for central sensitization and neuropathic pain. Pain. 2021;162(1):135-151. doi:10.1097/j.pain.0000000000002013

54. Hughes SW, Ward G, Strutton PH. Anodal transcranial direct current stimulation over the primary motor cortex attenuates capsaicin-induced dynamic mechanical allodynia and mechanical pain sensitivity in humans. Eur J Pain. 2020;24(6):1130-1137. doi:10.1002/ejp.1557

55. Kim MS, Koh IJ, Sung YG, Park DC, Na JW, In Y. Preemptive duloxetine relieves postoperative pain and lowers wound temperature in centrally sensitized patients undergoing total knee arthroplasty: a randomized, double-blind, placebo-controlled trial. J Clin Med. $2021 ; 10: 13$.

56. Mohamadi M, Rojhani-Shirazi Z, Assadsangabi R, Rahimi-Jaberi A. Can the positional release technique affect central sensitization in patients with chronic tension-type headache? A Randomized Clinical Trial. Arch Phys Med Rehabil. 2020;101(10):1696-1703. doi:10.1016/j.apmr.2020.05.028

57. Tavares DRB, Okazaki JEF, Santana MVA, et al. Motor cortex transcranial direct current stimulation effects on knee osteoarthritis pain in elderly subjects with dysfunctional descending pain inhibitory system: a randomized controlled trial. Brain Stimul. 2021;14(3):477-487. doi:10.1016/j. brs.2021.02.018 
58. Zheng $\mathrm{P}$, Jia S, Guo D, et al. Central sensitization-related changes in brain function activity in a rat endometriosis-associated pain model. $J$ Pain Res. 2020;13:95-107. doi:10.2147/JPR.S232313

59. Nijs J, Meeus M, Versijpt J, et al. Brain-derived neurotrophic factor as a driving force behind neuroplasticity in neuropathic and central sensitization pain: a new therapeutic target? Expert Opin Ther Targets. 2015;19(4):565-576. doi:10.1517/14728222.2014.994506

60. Klyne DM, Moseley GL, Sterling M, Barbe MF, Hodges PW. Are signs of central sensitization in acute low back pain a precursor to poor outcome? J Pain. 2019;20(8):994-1009. doi:10.1016/j.jpain.2019.03.001

61. Samad TA, Moore KA, Sapirstein A, et al. Interleukin-1beta-mediated induction of Cox-2 in the CNS contributes to inflammatory pain hypersensitivity. Nature. 2001;410(6827):471-475. doi:10.1038/35068566

62. Kohno T, Wang H, Amaya F, et al. Bradykinin enhances AMPA and NMDA receptor activity in spinal cord dorsal horn neurons by activating multiple kinases to produce pain hypersensitivity. J Neurosci. 2008;28(17):4533-4540. doi:10.1523/JNEUROSCI.5349-07.2008

63. Jiang LC, Wang ZZ, Peng TQ, Zhu JJ. The divided communities of shared concerns: mapping the intellectual structure of e-Health research in social science journals. Int J Med Inform. 2015;84(1):24-35. doi:10.1016/j.ijmedinf.2014.09.003

Journal of Pain Research

Dovepress

\section{Publish your work in this journal}

The Journal of Pain Research is an international, peer reviewed, open access, online journal that welcomes laboratory and clinical findings in the fields of pain research and the prevention and management of pain. Original research, reviews, symposium reports, hypothesis formation and commentaries are all considered for publication. The manuscript management system is completely online and includes a very quick and fair peer-review system, which is all easy to use. Visit http://www.dovepress.com/testimonials.php to read real quotes from published authors.

Submit your manuscript here: https://www.dovepress.com/journal-of-pain-research-journal 